\title{
Research on Internal Quality Assurance System of International Cooperative Joint-Programs
}

\author{
Haiying $\mathrm{Ma}^{1, \mathrm{a}^{*}}$ and Yajian Sun ${ }^{2, \mathrm{~b}}$ \\ ${ }^{1,2}$ School of Economics, Northwest Minzu University, Lanzhou (730124), P.R.China \\ aIxmahaiying8888@163.com, b 760336805@qq.com
}

\begin{abstract}
Keywords: Cooperative joint program; Internal quality assurance system; Quality system construction; Quality system evaluation
\end{abstract}

\begin{abstract}
International cooperation program can promote teaching reform and discipline construction, meet diverse learning needs and enrich personnel training mode. However, due to the failure to establish effective internal quality assurance system, it is difficult to accurately evaluate the progress and quality of joint program implementation. By combing the idea of establishing the quality assurance system, including the establishment of quality objectives, quality process, quality evaluation and feedback on the quality of the international cooperation joint program of internal quality assurance system, quality assurance system gives the evaluation model, a case study proves the effectiveness of the system model, to provide the technical means to improve the teaching quality of the level of international cooperation programs.
\end{abstract}

\section{Introduction}

Under the background of economic globalization and educational internationalization, international cooperative education program have been developing rapidly in China. The quality assurance of cooperative education program has increasingly become the focus of social attention. Chinese and foreign cooperatively run schools usually refer to the educational institutions of foreign cooperation with Chinese educational institutions in China, which take Chinese citizens as the main target of enrollment. The Chinese foreign cooperative education program refers to the education and teaching activities carried out by Chinese educational institutions and foreign educational institutions in terms of disciplines, majors and courses. The article mainly discusses the internal teaching quality guarantee of the latter.

Because of the short development time and lack of experience, there have been many problems in the development of cooperative education. First of all, in the management of international cooperation program, people initially focused on external quality assurance, such as the cooperative education evaluation organized by the Ministry of education and the quality certification being explored by social organizations. However, because of the large number of departments in charge, the management is confused. At the present stage of education evaluation and quality certification of international quality assurance are increasingly concerned about running the main internal system construction, such as higher education and professional certification audit Chinese currently ongoing, is leading people to pay more attention to the school internal quality assurance system construction, which is the international cooperation joint program to strengthen the construction of internal reasons quality assurance system. Secondly, under the framework of WTO, cooperation in running schools has been incorporated into the category of education service trade. Many institutions see it as an investment, and the aim is to gain profit. A lot of partners, driven by economic interests, blindly introduce foreign resources in spite of the quality of running schools and the characteristics of our school, so that the quality of joint program is low. From the perspective of western higher education development and successful experience, quality assurance should be transformed from external compulsive quality constraint to self regulation and restriction, and internal teaching quality guarantee mechanism should be built as a general self-discipline in universities. Although the evaluation of international cooperation program has also been taken seriously, the phenomenon of evaluation is relatively prominent, and achievement oriented is obvious, lack of introspection and introspection spirit, there is a phenomenon of intentionally concealing or 
analyzing deficiencies in school running. Therefore, it is of practical significance to improve the internal quality self-evaluation mechanism of the international cooperative running school and promote its active construction of the internal teaching quality guarantee system.

According to the literature survey, the research on cooperative education program mainly focused on macro policy background and system research, problems and countermeasures research, current situation and experience introduction, but few concerned about internal quality management of program. In order to improve the teaching quality of cooperative education, based on the concept of quality assurance system, the internal quality assurance system and evaluation model of international cooperation joint program were established.

\section{Construction Concept of Internal Quality Assurance System}

The Comprehensive Quality Management Cooperation. Quality construction, first of all, we should solve the problems of quality evaluation standards and the construction of quality assurance system. The quality of international cooperative schools depends on the quality of personnel training. And teaching is the most important way for talent training. The key factors affecting the internal quality of the joint program are the management factors such as teachers, students and teaching conditions.

The internal quality assurance as an international cooperation joint program for the sustainable development of the main strategy, help operators achieve regular diagnosis of key elements in the process of teaching, the teaching quality improved continuously; contribute to the realization of the teaching process management system, through the construction of quality culture, system construction, the formation of restraint and incentive mechanism comprehensive help to protect the interests of students and improve the reputation of cooperative education.

International cooperation joint program quality management from the concept of total quality management, through the analysis of the formation process of the quality, the key control points for the quality of teaching, use of the system, procedures, norms, culture and improve the implementation of the control, in order to achieve continuous improvement in quality.

Full System Guarantee. The whole system guarantee refers to the quality assurance of all levels and objects attached to the quality of the school running joint program. It should consider not only the quality of the sponsoring party, but also the quality of all elements, such as teachers, students, etc.

The internal quality assurance system of international cooperation in running schools is composed of many information entities from the perspective of information, including the main body of joint program management and the main body of joint program implementation. The construction of a quality assurance system requires a clear understanding of the relationship between these information bodies. The information main body of cooperative education joint program is divided into three parts, namely, the main body of management of both sides-managers and joint program executive bodies -teachers and students. In the research of quality assurance in cooperative education program, we should analyze them according to the information subjects, so as to analyze scientifically, reasonably and harmoniously, and guarantee the quality of program.

Total Process Management. The whole process of comprehensive quality management throughout the cooperation joint program, application, joint program implementation, each phase of the joint program summary of analysis, evaluation and improvement of joint program quality assurance in the joint program, the timely detection of problems and deficiencies, and make adjustments to ensure quality requirements of each stage.

Omni bearing Responsibility. All directions mean that the research work of a cooperative school joint program needs comprehensive and multiple considerations. The quality of school running program is closely related to various information elements. In the course of joint program, the quality of the whole school joint program may be affected by the improper coordination of information elements. A quality problem may be caused by one or more information elements, and may also be caused by a variety of factors that are incompatible with each other. Therefore, in the research of quality assurance of school program, we need to consider all the quality information elements of different processes and achieve scientific management in the whole process of running schools. 
Full Characteristic Concept. The concept of full characteristics is designed and analyzed in a cooperative school joint program which takes into account the special characteristics and general characteristics of information elements at various levels. In the process of evaluation, it is necessary to collect the information objects of each information subject, that is, the characteristics of the information subject. Here, it is generally divided into three types of general properties, namely, physical properties, process characteristics and capability characteristics. These three general-purpose features can cover all information of the information body, which is beneficial to the collection and classification of information elements. The general characteristics of each information body have its own specific characteristics. The system theory of joint program is a systematic joint program, and the internal quality assurance system of the cooperative running school can be regarded as a complex system. According to the system theory, a complete system consists of target system, process system, evaluation system and feedback system. The subsystems are not independent of each other, they are interrelated and mutual mapping, the function of each subsystem and task and other systems overlap together, each other base and support each other.

\section{Operation Model of Internal Quality Assurance System}

The construction and improvement of the internal quality assurance system is the key factor for the quality assurance in the joint program of running a cooperative school. The joint program internal quality assurance system of cooperation around the quality target specific work, for the realization of student satisfaction with relevant parties to complete the process required by the school personnel, equipment, information, energy and other auxiliary devices, as well as teaching methods, teaching content, management norms etc. is an organic whole with specific function.

The Goal of Joint-program is the Target for the Internal Quality Assurance System. The two sides should establish school running ideas and concepts, locate their own school running characteristics, formulate cooperative development strategy report and teaching evaluation report, etc., and relevant teaching staff should set up corresponding teaching curriculum plans according to their objectives.

The Process of Education Corresponds in the System Structure. It is embodied in the following aspects:

Information Input. To ensure the quality of the students and select the suitable source for the joint program to build a high quality teacher team and to equip the teaching resources and to determine the reasonable standard of charge.

Information Process. We should optimize the teaching process, including the optimization of teaching curriculum, the reasonable arrangement of class hours and school system, the adoption of teaching materials, the scientific advanced teaching methods, and so on.

Information Output. The establishment, supervision and control of students' study results of academic evaluation.

Quality Evaluation Student and Related Parties Satisfaction. The beneficiaries of quality and efficiency of school running program are students and joint program stakeholders. Therefore, it is reasonable to evaluate the quality of the whole school joint program through the satisfaction degree of students and related parties to the elements of the school running system.

In order to ensure the quality of the output of school running program, the subject of joint program management generally needs three stages of evaluation: pre evaluation, middle evaluation and post evaluation. The evaluation means to evaluate the application of target efficiency, supporting conditions and implementation environment, and provide scientific basis for the development of the joint program plan; evaluation is to evaluate the research objectives, research program in the process of planning, organization and management, environmental conditions, and provide the basis for the joint program quality plan adjustment; post evaluation mainly refers to the objective analysis to the completed joint program objective, system implementation, effectiveness and effect of, and through feedback to improve decision-making level of education for the purpose of joint program management. According to the forming process of the quality, in view of the key control points of the quality of the joint program, some evaluation indexes are selected to evaluate the running situation of the cooperative school running 
program. The paper mainly uses the analytic hierarchy process to determine the weight of each index, and then evaluates the quality of the school joint program by the fuzzy comprehensive evaluation method which is divided by experts.

The Feedback System. In view of the results of the evaluation, the weak links in the quality of school running program are found, and suggestions for improvement are put forward. The link with feedback and radiation, plays a role in the improvement and supervision of internal quality assurance system of cooperative program in general are conference organization, student evaluation etc., can also use questionnaires or interviews regularly informed of relevant parties on the cooperative education program to ensure the quality of the satisfaction.

\section{Evaluation Model of Internal Quality Assurance System}

The internal quality assurance system, the construction of cooperative education joint program first, cooperation between the two sides should establish a unified cooperative education joint program quality objectives; secondly, through the analysis of the formation process of quality research cooperation joint program, to find critical points affecting the quality, the establishment of quality standards, quality information collection; finally, the key control points, select the appropriate index the implementation of quality assessment, management and feedback control is applied to quality, thus forming a continuous improvement and improve the quality of the atmosphere.

Joint program management includes the unit cooperation education joint program, joint program execution is the main teaching staff and students, from the information point of view, they are the three main information cooperation joint program quality assurance system; from the general characteristics of each subject, three kinds of information have common characteristics, namely the process capability and characteristics of information and information the physical characteristics of information; special feature is a characteristic information for a subject specific information, the model can comprehensively collect various indicators of internal quality education program. For example, for the student body of the joint program executive, the material characteristic information includes student's course achievement, process characteristic information, usual performance, and ability characteristic information, including student's foreign language level and professional ability.

Table 1 Evaluation information content of internal quality assurance system

\begin{tabular}{|c|c|c|c|}
\hline main body & Physical information & Process information & Ability information \\
\hline \multirow{3}{*}{$\begin{array}{l}\text { joint } \\
\text { program } \\
\text { manager }\end{array}$} & The goal of joint program & management training & fund management \\
\hline & Rules and regulations & \multirow{2}{*}{ Review and update } & Qualification of joint \\
\hline & Hardware condition & & program \\
\hline \multirow[b]{2}{*}{$\begin{array}{l}\text { Teaching } \\
\text { staff }\end{array}$} & Number of Teachers & Teaching plan & teaching level \\
\hline & Proportion of Teachers & $\begin{array}{l}\text { Content of courses } \\
\text { teaching effectiveness }\end{array}$ & Scientific research level \\
\hline \multirow{2}{*}{ Students } & Curriculum achievement & Ordinary performance & Professional competence \\
\hline & Practice assessment & Student satisfaction & Foreign language level \\
\hline
\end{tabular}

\section{Conclusions and Suggestions}

This paper reviews the construction of comprehensive quality management and quality assurance system such as the system theory concept, on this basis, including the establishment of international cooperation joint program quality objectives, quality process, quality assessment and quality feedback in one of the school joint program internal quality guarantee system, and gives the evaluation of internal 
quality assurance system of cooperative program model. The internal quality assurance system of the cooperative school joint program proposed in this article has certain practical significance and applied value. The internal quality assurance system based on information system feedback model can integrate joint program quality objectives, quality processes, quality evaluation and feedback. Through the information evaluation model, the key indicators that affect the school running joint program are collected in an all-round way. In this case, a variety of indicators are selected mainly for information input, execution process and information output in three aspects. However, due to the qualitative concept of school running program, most of the indicators selected in the article are qualitative indicators.

\section{Acknowledgements}

This work was supported by the Pilot joint program of comprehensive professional reform of International Economics and Trade (Joint Program, USU and NWUN) (Grant No:2017XJZYZHGGSD-01) and by Research joint program on education and teaching reform (Grant No:2017XJJG-12) of the Northwest Minzu University.

\section{References}

[1] Liang Yan, on the construction of China's quality guarantee system for Chinese and foreign cooperation in running schools, Beijing: University of International Business and Economics, 2006.

[2] Chen Yukun, An introduction to the quality assurance system of higher education. Beijing: Beijing Normal University press, 2(2015)12-19.

[3] Lin Jinhui, Liu Meng, A summary of the fourth national Chinese foreign cooperation annual meeting, Education Research, 4 (2014)157-163.

[4] Lin Jinhui, Liu Meng, the basic elements and paths of internal teaching quality assurance in Chinese foreign cooperative education program in Chinese universities, Chinese Universities, 4 (2012)60-71.

[5] Wang Liang, Significance and implementation of teaching evaluation system in Chinese foreign cooperative education. Journal of Nanjing University of Science and Technology: Social Science Edition, 6 (2004)75-81.

[6] Li Ming, Research on internal teaching quality monitoring system in Chinese research universities. Journal of Beihang University: Social Science Edition, 1 (2014)106-107..

[7] Buddha Zhaohui, Cooperative universities construction quality assurance system at home and abroad, Research of Higher Engineering Education, 6 (2006)52-59.

[8] Dai Wei, Research on Modeling and operating mechanism of quality technology system. Quality and Reliability, 1 (2013)27-31.

[9] Wang Shi Hui, Evaluation method of science and technology joint program. Beijing: Science Press, 3(2003)20-29.

[10] Yin Yongjian, Quality evaluation of Chinese and foreign cooperative schools in Shaanxi University, Journal of Engineering of Xi'an University, 8 (2009)107-110. 